\title{
Study on the Application of Microteaching Method in the Popularization of Sports Table Tennis in Colleges and Universities in Southwest China
}

\author{
Jun He, Jiajia Li \\ Southwest Petroleum University-Nancong Campus, Nanchong, Sichuan,637000, China.
}

Keywords: table tennis and its teaching characteristics; The characteristics of the micro-teaching method; The application of microgram teaching method in table tennis teaching.

\begin{abstract}
Along with the rapid development of science and technology, teaching methods and teaching methods are also progressing and developing. Microteaching is a combination of modern communication technology and people's education concept. The micro-teaching method, as the name suggests, is a new kind of micro-teaching method. Of course, the advanced factors in the traditional teaching, or its use in the micro-standard teaching method, it is the teaching principle of the main modern teaching theory as the foundation, use of modern advanced information and communication technology and audio-visual technology, through the teaching of timely feedback, timely feedback of teaching for teachers' teaching training and teaching evaluation. Micro-standard education law formed in the United States, the concrete can be traced back in the $60 \mathrm{~s}$, through the teaching method greatly improve the comprehensive quality of the teachers, in the $70 \mathrm{~s}$, western countries found out the advantages of this teaching method, to follow suit, the spread of the micro-standard teaching method are in the process of development and perfection. On behalf of George brown of Britain have been, he thought preparation, perception, coach, is the three elements in micro-standard method of teaching, the idea can be said to be the influence in the whole of the UK and Europe, since then, ninety percent of the British teacher training schools have established the micro-standard teaching course, and it affects the whole world. In the 1980s and 1990s, China's education sector also introduced this teaching method. The implementation of this method is relatively late in China. In the 1990s, some teachers' schools in Beijing were able to implement this teaching training method. Southwest region in the common course for the college sports table tennis also can carry out this teaching method, this paper combines the actual conditions of micro-standard education law in the common course for the college sports table tennis in southwest made specific research the application and practice, for your reference.
\end{abstract}

\section{Introduction}

Micro-standard teaching method, is a miniature mode of teacher training, but it cannot only use in teachers' training, applied in students also can get surprise effect, because it will become can control the training process, can control, can not only improve the efficiency of the training, also can improve the learning enthusiasm of trainee, save manpower, material resources and time. Through the corresponding communication equipment and communication technology, the teaching equipment can be taught in stages and can be effectively taught in a certain course. In recent years, the rapid development of national economy in China, people's living standard gradually improve, along with the improvement of people's living standard, people's life is no longer limited to the life and work, they began to attach importance to entertainment, sports is occupied the most proportion in the entertainment, table tennis is the national sport of China, it is showing repeatedly in the world series, along with the expansion of international influence, table tennis and table tennis exercise on site and equipment requirements is low, its mass base is also more and more wide, especially in the southwest of colleges and universities, the share of it in the entertainment life is becoming more and more big, it must cause the attention of the educators, because students a correct concept of sports, to a person's development is very important in the future, which requires the educators must improve their professional knowledge, to update their teaching ideas, committed to the development and perfection in the common course for the table tennis. 


\section{The Origin and Teaching of Table Tennis.}

\subsection{The Origin and Development of Table Tennis.}

The development of table tennis can be said to be relatively long. The sport was first invented in England. It is said that the production of table tennis is still a coincidence and is quite magical. Concrete after something like this: the two lads because of bad weather comes to suspend the tennis match, but in the process of the effort of two young men refused to throw in the towel, took shelter from the rain spell up two tables in the room, in playing table tennis, a dozen unimportant, a dozen produced the prototype of the table tennis, the ball games also because of its high interest, popular in the whole of Europe, later, a person accidental travel in England found a kind of hollow ball toys, the toy ball flexibility is moderate, unlike tennis elastic is too large, difficult to control, so more suitable to play on the table, so gradually replace the rubber ball and tennis, since then, table tennis pop up all over the world, the name of the table tennis also because to produce sound when struck. Table tennis is not only a sport with high interest, but also is beneficial to human health, often play table tennis can prevent myopia, improve the respiratory system, can improve blood circulation system, the movement of the table tennis is a beneficial to health of body and mind, so to speak. At first, table tennis is the British royal family and aristocrat's entertainment game, then with the incoming folk, civilian, gradually become the masses of the people, old and young all appropriate, popular sport.

\subsection{Table Tennis Teaching.}

The first is to focus on practicality. Table tennis ball method and technique can be said to be more diverse, and, table tennis is an intelligent, skill, physical activity, intelligence is the core of it. it is characterized by fast speed, many changes and strong hitting skills. Is also precisely because of these reasons led to a higher rate of fault tolerance and fault tolerance rate is higher on the teacher's teaching level also had the higher request, traditional way of table tennis teaching is relatively rigid, plus is due to the teaching in colleges and universities students have generally into adulthood, personality is bright, the traditional teaching method not only cannot mobilize students' learning enthusiasm, and unable to achieve the ideal teaching effect, how to become rigid boring traditional teaching class lively and interesting, is each person must solve the problem of education in colleges and universities. The first is to reform concept, colleges and universities from the field environment is different, the teaching requirement to change the idea, change of competitive sports for fun games, at the same time also should pay attention to emphasize competition second, friendship first, through the sports to strengthen students' physical quality, but also can strengthen the friendship between classmates. The second is to change the teaching method, cannot blindly according to the traditional teaching method, pass only book knowledge, to strengthen the teaching effect by using the method of precept, abstract to concrete, intuitive can not only take care of most people, but also can strengthen the teaching effect, strengthen students' learning. This method can not only deepen students' learning impression, but also arouse students' interest in learning, which is conducive to building a harmonious and stable classroom environment. Also, should pay attention to their own practice, students' errors by imitation action, sets up the cautionary tale, not only can achieve better teaching quality, at the same time can also close the relationship between teacher and student, is conducive to the establishment of a harmonious relationship between teachers and students. Is the most important is the third point, want to timely inspection and reflection of the teaching effect, the most effective way is to undertake to the student test and detection, through the test results can learn short board, each student will also learn about teaching the existence of loopholes, this mechanism is beneficial to teaching smoothly, so it is worthy of promotion.

\section{The Characteristics of the Micro-Teaching Method.}

\subsection{Clear Objectives.}

Micro-standard teaching method is different from other teaching methods, in the beginning there was more clear goals, it is because there is a clear goal, also makes the micro-standard teaching method has a high operational, micro-standard teaching goal is not a one-time is the ultimate goal, but the big goal is decomposed into many small target, and then determine the ultimate goal of the 
last, this method can not only make every teaching link has reasoned, also can harvest feeling of success in the success step by step, this to each student's physical and mental development is also very good, so is very beneficial to improve teaching quality.

\subsection{Small Scale}

The micro-standard teaching method different from the traditional teaching method, is not a big class teaching and classroom teaching, on the contrary, it is a small class teaching, the classroom is not only confined to the traditional classroom, are generally will all grouping, and then study in group of three to five, which makes everyone the opportunity to actively participate in learning, the teaching mechanism compared with traditional or other teaching method is more flexible, everyone has the opportunity to sum up experience, also have the opportunity to perform on stage since 1960 and do respect differences, can good care to the deficiency of some students, so this is also the micro-standard teaching a superior place.

\subsection{It Has Modern Audio and Video Technology.}

The formation and development of the micro-standard teaching method has the very big factor on the one hand to modernize the audio-visual technology, modern audio-visual technology not only can use the advanced modern technology, auxiliary teaching, give students the feeling that find everything new and fresh, but also can record every student's learning process, provides not only a reflection of the platform, on the other hand, will help build a good learning atmosphere. After class, each student has a chance to reflect on the deficiencies in his learning process and provide sufficient information for self-assessment. As the saying goes, a distance, the outsider, using the modern audio-visual technology can have the effect of the beholder, on the other hand, are largely reduces the guidance of teachers' teaching pressure. These video data can not only produce certain teaching effect on the parties, through to the video data to sort and compilation, can also for later students produce certain teaching effect, become the micro-standard teaching method of the second classroom.

\subsection{Perfect Evaluation Mechanism.}

The traditional teaching mechanism is more abstract, most of which can only rely on experience and feeling. The mechanism is clearly unfair. There may be some students who have a good relationship with the instructor, and their scores and evaluations are higher, which is unfair to others. This situation can be fully resolved in the micro-teaching method. The evaluation mechanism in micro-teaching method is relatively objective and fair, because it adopts the combination of selfevaluation and collective evaluation, and the combination of evaluation and discussion.

Moreover, because of the video assisted learning, it makes the evaluation more objective and fair, and more targeted. In addition, with the development of computer technology, but also for the microstandard teaching evaluation system to broaden another road, the last of the result of teaching data can be obtained by computer, which makes the final evaluation result more reasonable objective. A fair and reasonable evaluation system has an important position in the micro-standard teaching system, the establishment of the evaluation system is not so easy, so a complete evaluation system is the difficulty in the micro-standard teaching, is the key.

\section{The Application of Microteaching Method in Table Tennis Lessons.}

Micro-standard teaching method, just as its name implies, micro, it is the meaning of small, is the meaning of new-Confucianism, is also studied and discussed the meaning, the micro-standard teaching method is easy to understand approach to make the complex difficult to understand the teaching process into a simple teaching stage, so it can be tested for each stage of teaching, is conducive to the improvement of teaching quality finally. In table tennis teaching is more complex, it is also because table tennis has high operability, when the micro-standard teaching method is more practical, on the one hand, through the teacher's own professor, teach students the correct style or dribbling method, if the students appear a mistake, the teacher can also set an example, demonstrate the correct style, give the students correct method, also can take advantage of the micro-standard teaching method at the same time, the first is to decompose the teaching, it not only reduces the difficulty of teaching, but also can improve the students' learning efficiency and teaching through decomposition, can largely reduce the teacher's teaching burden; The second is small, can participate 
in, the micro-standard teaching different traditional big class teaching, but can take care of a lot of students, let they participate in the process of understanding, can not only improve the students' participation, also can improve the learning efficiency of students at the same time, can say is kill two birds with one stone. The third is to use the micro-standard teaching of advanced modern audio-visual equipment, before no micro-standard method of teaching, the traditional teaching method is too abstract, students cannot understand from the teacher in the teaching of comprehensive knowledge, and in the micro-standard teaching method, it can be easily resolved, micro-standard teaching method by relying on modern audio-visual equipment, can use audio-visual teaching to the student the feeling that find everything new and fresh, but also can be the embodiment of the specific teaching content image in front of students, vivid images and modern communications equipment, can greatly improve the students' study enthusiasm. The fourth is the micro-standard method of learning evaluation system in a timely manner, the micro-standard teaching evaluation system is not the examination mechanism in the traditional teaching, also is not pure level mechanism, the micro-standard teaching evaluation system is the product of self-evaluation and collective evaluation, evaluation system and not just appraisal, also indirectly have comment, this makes the more reasonable and objective evaluation system, makes the students' table tennis technology in constant development and progress in the evaluation.

\section{Conclusion}

Micro-standard method of teaching is a teaching method which emerged only in recent years, the reasonable use of this method is advantageous to the teaching level of teachers is also can be applied to the broad masses of students, to make full use of this method is superior, foster strengths and circumvent weaknesses, can't let his own subjective impression has affected the objective results. Also, the actual investment, since the adjust measures to local conditions, to paraphrase cannot stand still, this method is not only unfavorable to the participants improve the teaching effect, at the same time also does not favor the micro-standard teaching development and perfect.

It is important to understand the characteristics of the microgram teaching method, such as the clear goal, such as the perfect evaluation mechanism, which are worthy of our attention. Microstandard teaching method has since produced walk on the way of development and perfection but is also in constant development and progress of society, how to let the micro-standard teaching method adapted to the continuous development of the social status is worth a person's thinking.

Therefore, it is a long way to go for the development of micro-teaching. We should combine the practical reality and continuously promote the development and progress of the micro-teaching method.

\section{References}

[1]. Quansheng Wang. Application of PDCA circulation method in the teaching of education professional table tennis in universities [D]. Journal of Chengdu Sport University, 2016.

[2]. zhou jie. The application of "multi-ball + cooperative" teaching mode in the teaching of table tennis in sports colleges [D]. Wuhan institute of physical education, 2011.

[3]. zhang zhu ping. Experimental research on the teaching of the micro-teaching method in the professional football of education professional football in universities [J]. Guide of Sci-tech Magazine, 2012(20):21-22.

[4]. li qiang, yu dong. Experimental study on the teaching effect of the teaching of education professional track and field students in our hospital $[\mathrm{J}]$. Journal of Nanjing Sport Institute (Natural Science), 2009, 8(2):68-70. 